\title{
Rancang Bangun Game Bergenre Role Playing Game Cerita Rakyat Sangkuriang
}

\author{
Dewi Tresnawati ${ }^{1}$, Iqbal Setyawan ${ }^{2}$ \\ Jurnal Algoritma \\ Sekolah Tinggi Teknologi Garut \\ J1. Mayor Syamsu No. 1 Jayaraga Garut 44151 Indonesia \\ Email : jurnal@sttgarut.ac.id \\ ${ }^{1}$ dewi.tresnawati@sttgarut.ac.id \\ 21606063@sttgarut.ac.id
}

\begin{abstract}
Abstrak - Perkembangan game di Indonesia cukup pesat hingga menjadikan game sebagai bagian dari kehidupan yang sulit terpisahkan dari kehidupan masyarakat modern sebagai sarana penyampaian informasi yang lebih interaktif, ataupun juga sebagai sarana alternatif hiburan bagi kalangan muda hingga dewasa. Role Playing Game merupakan game berbasis strategi yang cukup populer, di dalamnya terkandung nilai seni peran dan cerita yang dapat membuat pemain merasakan menjadi seperti seorang tokoh dalam suatu cerita, dan juga membuat pemain mengenal tokoh pada cerita tersebut. Indonesia memiliki kekayaan yang sangat berlimpah akan wisata, budaya, bahasa, dan legenda serta cerita rakyatnya. Akan tetapi seiring kemajuan zaman dan perkembangan teknologi, banyak dari masyarakat Indonesia tidak mengetahui hal tersebut karena lebih tertarik oleh media hiburan lain yang menarik. Dari permasalahan tersebut memunculkan gagasan untuk membuat game yang dapat mengenalkan tentang salah satu cerita rakyat yang berjudul Sangkuriang. Metode yang digunakan dalam penelitian ini adalah Digital Based Game Learning-Instructional Design, pengujian aplikasi ini hanya menggunakan metode Alpha Testing. Penelitian ini menghasilkan aplikasi game cerita rakyat Sangkuriang yang dikemas ke dalam bentuk aplikasi Android. Dengan adanya game ini di harapkan dapat menjadi referensi dalam membantu masyarakat umum khususnya generasi muda untuk mengenal cerita rakyat Sangkuriang.
\end{abstract}

Kata Kunci - Digital Based Game Learning-Instructional Design; Game; Role Playing Game; Sangkuriang.

\section{PENDAHULUAN}

Perkembangan game di Indonesia cukup pesat menjadikan game sebagai bagian dari kehidupan masyarakat modern yang yang sulit untuk dipisahkan sebagai sarana penyampaian informasi yang lebih interaktif, ataupun juga sebagai sarana alternatif hiburan untuk semua kalangan. Banyak perusahaan luar yang menjual game buatan mereka untuk dipasarkan di Indonesia dan salah satu jenisnya adalah game RPG (Role Playing Game). RPG merupakan game berbasis strategi, di dalamnya terkandung nilai seni peran dan cerita yang dapat membuat pemain merasakan menjadi seperti seorang tokoh dalam suatu cerita, dan juga membuat pemain mengenal tokoh pada cerita tersebut. Game RPG berlangsung dalam susunan dunia realistis dan bentuk tertentu, atau dalam dunia imajinasi dengan diwakili oleh karakter yang bisa membuat kita berpikir serta memecahkan berbagai tugas sepanjang perjalanan permainan [1]-[5]. Indonesia memiliki kekayaan yang sangat berlimpah akan wisata, budaya, bahasa, dan legenda serta cerita rakyatnya [6]. Seiring kemajuan zaman dan perkembangan teknologi menyebabkan unsur-unsur budaya lokal semakin terkikis. Masyarakat Indonesia banyak yang tidak mengetahui akan cerita rakyat karena lebih tertarik pada media hiburan lainnya yang lebih menarik, padahal cerita rakyat memiliki nilai-nilai khas akan kearifan lokal budayanya. Cerita 
rakyat juga mengasah kreativitas dan imajinasi karena cerita rakyat mengandung nilai edukatif yang dapat mendidik moral dan karakter generasi muda, maka dari itu cerita rakyat harus tetap dilestarikan [7][8].

Terdapat beberapa penelitian sebelumnya yang akan menjadi rujukan, pada penelitian pertama yang berjudul "Aplikasi Game Cerita Rakyat Bali Sebagai Sarana Pendidikan Karakter Anak Berbasis Mobile" terdapat 3 jenis mini game yang diselipkan pesan moral pada masing-masing akhirnya, penelitian tersebut menggunakan metode waterfall [7]. Pada penelitian kedua yang berjudul "Game Edukasi rpg Matematika" pemain hanya perlu menjawab soal matematika sederhana untuk menyelesaikan game [2]. Pada penelitian ketiga yang berjudul "Pembuatan Game Bergenre Tower Defense Dengan Judul "Selendang" Untuk Melestarikan Cerita Rakyat Jaka Tarub Bagi Anak" mengusung tema Tower Defense pada game-nya [8]. Pada penelitian keempat yang berjudul "Game Endles Runing Si Kancil Menggunakan Finite State" mengusung Endeless Runner sebagai temanya [6]. Pada penelitian kelima yang berjudul "Perancangan Dan Pembuatan Game Edukasi Pencegahan Nyamuk Demam Berdarah Berbasis Android" menyebutkan bahwa konsep perpaduan antara materi dan game menjadikan aplikasi tersebut interaktif dan lebih menarik minat pemain untuk membaca materi yang disampaikan [1]. Serta pada penelitian keenam yang berjudul "Rancang Bangun Game Edukasi Sistem Tata Surya" menjelaskan bahwa metode DBLG-ID memiliki beberapa tahapan yang terdiri dari analisys; design; development; quality assurance; dan implementation and evaluation phase[9]. Tujuan dari penelitian ini ialah untuk merancang dan membangun aplikasi game bergenre Role Playing Game (RPG) tentang salah satu cerita rakyat Indonesia yaitu Sangkuriang. Metodologi yang digunakan pada penelitian ini adalah Digital Based Game Learning-Instructional Design (DGBL-ID). DGBL-ID merupakan pembelajaran berbasis game digital yang bertujuan untuk menghubungkan komputer atau video game dengan konten pendidikan, dan dapat digunakan di hampir semua mata pelajaran dan tingkat keterampilan [10].

\section{METODE PENELITIAN}

Perancangan dan pembangunan game cerita rakyat Sangkuriang bergenre RPG ini menggunakan DGBL-ID sebagai metodologinya. DGBL-ID terdiri dari lima tahapan dimulai dari analysis phase hingga implementation and evaluation phase [11].

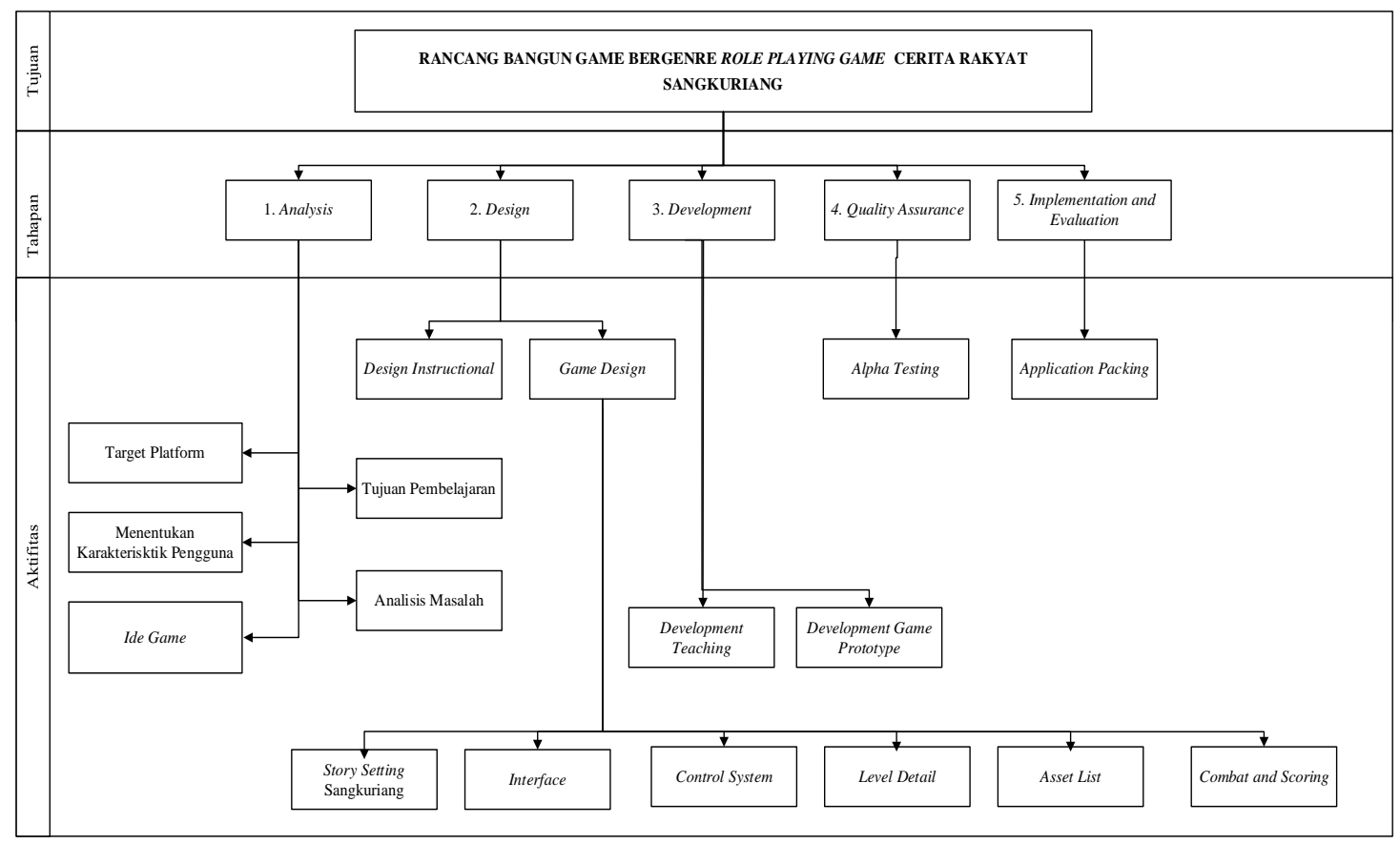

Gambar 1: Work Breakdown Structure 
Adapun tahapan berdasarkan Gambar 1, adalah sebagaimana berikut:

1) Analysis Phase, pada tahapan ini analisis mengenai target platform, karakteristik pengguna, ide, analisis permasalahan, dan tujuan pembelajaran sudah mulai dilakukan. Setelah selesai pada tahapan Analysis Phase, maka selanjutnya akan dilakukan Design Phase;

2) Design Phase, setelah melakukan tahap Analysis Phase maka langkah selanjutnya yaitu merancang Game Design, Combat and Scoring System, Interface, Control System, Level Detail, Asset List, Story Setting dan Design Instructional. Perancangan menghasilkan Work Breakdown Structure yang disusun dari rancangan activity sequence dan detail activity;

3) Development Phase, dari hasil Design Phase yang telah dibuat, langkah selanjutnya yaitu melakukan penerapan setiap scene dengan memasukkan objek multimedia yang akan digunakan;

4) Quality Assurance Phase, pada tahapan ini aplikasi sudah mulai di uji, adapun konsep pengujian yang akan dilakukan, yaitu dengan pengujian Alpha;

5) Implementation and Evaluation Phase, setelah berhasil melakukan tahap Quality Assurance, maka tahap selanjutnya adalah melakukan tahap Implementation and Evaluation, pada dasarnya tahapan ini dibagi menjadi dua tahapan, yaitu Launching dan Evaluation and Modification. Namun penelitian ini hanya akan melakukan packing aplikasi kedalam bentuk APK dan tidak melakukan launching.

\section{HASIL DAN PEMBAHASAN}

\section{A. Hasil}

Penelitian ini mengikuti tahapan-tahapan yang terdapat di dalam metodologi DGBL-ID, yaitu: analisys; design; development; quality assurance; dan implementation and evaluation phase.

1) Analisys Phase dilakukan untuk menentukan tujuan pembelajaran dari game yang akan dibangun, mengidentifikasi karakter pengguna, menentukan target platform, dan ide game.

2) Design Phase dilakukan untuk merancang kebutuhan-kebutuhan untuk membangun game dengan mengacu pada tahap game design dan instructional design.

a Instructional Design terdapat empat aspek utama, yaitu: Tujuan khusus; Tujuan umum; Materi; dan Metode pembelajaran [12]. Berikut adalah penjelasan tentang instructional design yang telah dibuat sesuai dengan tujuan pada tahap analysis phase. Tujuan Utama: Pengguna dapat mengenal cerita rakyat Sangkuriang. Tujuan Khusus: Mengetahui asal usul tokoh Sangkuriang; Mengetahui asal usul terbentuknya gunung Tangkuban Parahu; Menerapkan nilai-nilai kearifan lokal dalam cerita Sangkuriang. Materi : Pengenalan dan simulasi cerita rakyat Sangkuriang. Metode: Cerita; Simulasi dan; Permainan.

b Game Design dilakukan untuk merancang fitur-fitur yang terdapat pada game. Design Game terdiri dari beberapa tahapan:

1. Story Setting adalah merancang alur jalannya cerita yang akan diterapkan kedalam game;

2. Combat and Scoring, pengguna diharuskan mengikuti alur cerita dengan sejumlah misi yang terpadat di dalamnya, jika berhasil menyelesaikan misi maka akan mendapatkan exp yang berguna untuk menaikan kemampuan karakter di dalam game;

3. Control System, game ini menggunakan touchscreen untuk menjalankan dan menggerakkan karakternya;

4. Level Detail, adalah merancang design tempat berdasarkan design story yang telah dibuat untuk mendukung jalannya cerita dan misi di dalam game;

5. Interface dari game cerita rakyat Sangkuriang ditentukan berdasarkan hasil dari tiga design sebelumnya, yaitu story setting, combat and scorring, dan level detail. Secara garis besar, rancangan dari interface ini terdiri atas: menu utama; in game menu; dan gameplay. Rancangan interface menu utama terdiri dari empat pilihan yaitu: New Game; Continue; Option; dan Exit Game. 


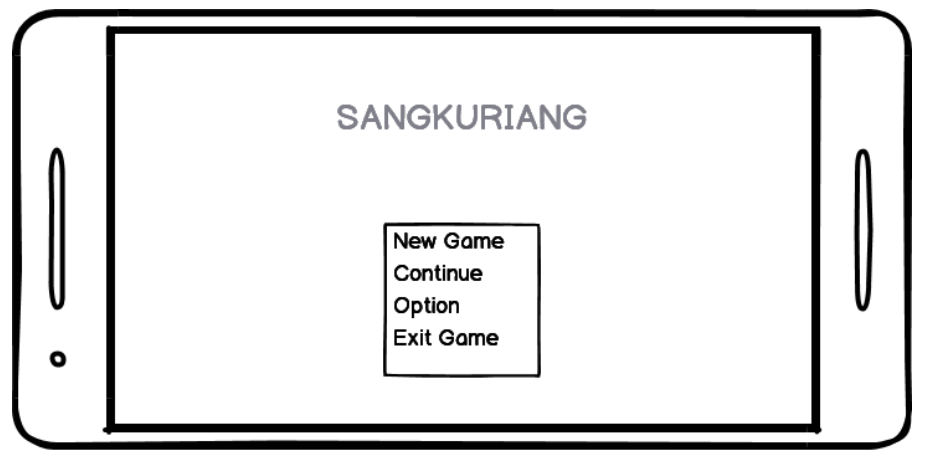

Gambar 2: Menu Utama

6. Asset List, dilakukan untuk mendata dan mengumpulkan semua bahan-bahan yang digunakan dalam merancang dan membangun game.

3) Development Phase, terdiri dari tiga tahapan yaitu:

a Develop Lesson Plan for History Subject. Pada tahap pengembangan game cerita rakyat Sangkuriang ini rencana pembelajaran dimuat ke dalam bentuk cerita;

b Develop Teaching Resources. Pengembangan materi pada game Cerita Rakyat Sangkuriang menggunakan beberapa sumber untuk dapat digunakan sebagai materi pembelajaran, yaitu: Buku Seri Cerita Provinsi Jawa Barat: Sangkuriang dan Dayang Sumbi (2019) karya TIM S.M.I.L.E.; dan Film Sangkuriang (1982) karya I. Sukardjasman;

c Develop Game Prototype. Pengembangan dari game Cerita Rakyat Sangkuriang menggunakan RPG Maker MV. Pada tahap ini, game sudah dapat di mainkan dari awal hinga akhir.

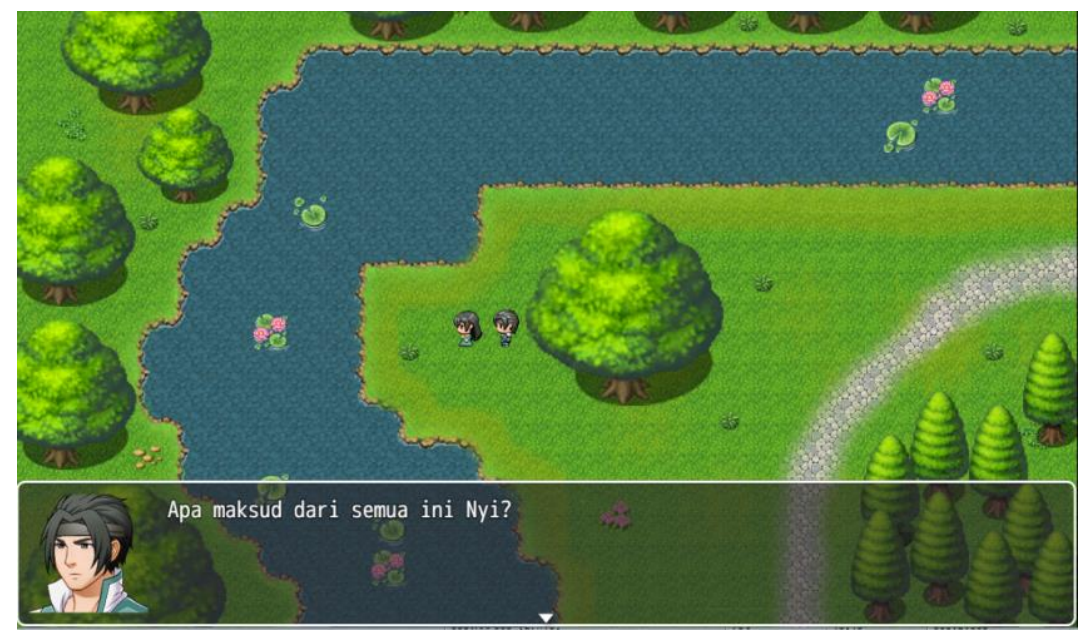

Gambar 3: Gameplay

4) Quality Assurance Phase. Pada tahap ini, dilakukan pengujian game apakah yang telah dibangun dapat berjalan sempurna sesuai dengan rancangan yang dirancang sebelumnya. Metode alpha testing digunakan dalam tahap ini menggunakan tiga versi android, metode pengujian ini dilakukan oleh pihak pengembang untuk menguji apakah game berfungsi secara sempurna. Hasil dari Alpha Testing game cerita rakyat Sangkuriang, semua fitur yang terdapat pada game telah berjalan dengan baik, akan tetapi salah satu fungsi yang terdapat pada game yaitu fungsi exit game tidak dapat berjalan dengan baik di beberapa device dikarenakan perbedaan dukungan dari masing-masing vendor device tersebut. 
5) Implementation and Evaluation Phase terdiri dari dua tahapan yaitu Launcing dan Evaluation and modification, akan tetapi pada tahap ini hanya akan dilakukan packing aplikasi ke dalam bentuk .apk dan tidak membahas tentang Evaluation and modification.

\section{B. Pembahasan}

Hasil penelitian adalah game cerita rakyat Sangkuriang bergenre RPG. Tujuan dari penelitian ini adalah untuk mengenalkan dan juga melestarikan nilai kearifan khas budaya lokal yang ada pada cerita rakyat Sangkuriang kepada masyarakat umum khususnya kepada generasi muda. Untuk mengetahui keselarasan hasil dari penelitian yang dilakukan dengan penelitian terdahulu, maka harus di lakukan perbandingan antara kedua penelitian tersebut. Pada penelitian pertama [7] menghasilkan game untuk anak usia 6-12 tahun sedangkan metodologi yang digunakan adalah waterfall. Pada penelitian kedua [2] telah membangun game bergenre RPG sebagai media pembelajaran mengenai pengoperasian matematika sederhana dengan metodologi kuantitatif. Pada penelitian ketiga[8] telah membangun media pelestarian cerita rakyat Jaka Tarub. Pada penelitian keempat [6] telah membangun game bergenre endeless running dengan tujuan untuk mengimplementasikan metode Finite State Machine. Pada penelitian kelima [1] telah membangun game dengan tujuan untuk menyampaikan materi tentang 3M demam berdarah dengan menggunakan metode Research and Development. Dan penelitian keenam [9] telah membangun aplikasi pembelajaran tentang tata surya menggunakan Unity sebagai engine game-nya. Kemudian perbedaan dari penelitian yang dilakukan dengan penelitian terdahulu yaitu dirancang dan dibangunnya game bergenre RPG yang membahas tentang cerita rakyat yang ada di Indonesia, dengan menambahkannya fitur battle system untuk menarik minat pengguna memainkan game ini.

\section{KESIMPULAN DAN SARAN}

\section{A. Kesimpulan}

Berdasarkan pada hasil dan pembahasan, bahwa penelitian ini menghasilkan media pembelajaran berupa game yang dibangun yang bertujuan untuk mengenalkan tentang cerita rakyat Sangkuriang kepada masyarakat umum, khususnya generasi muda. Aplikasi game juga di bangun ke dalam platform android, hal ini bertujuan agar pengguna bisa lebih mudah untuk mengoparsikannya.

\section{B. Saran}

Game cerita rakyat Sangkuriang ini memiliki beberapa saran pengembangan, oleh karena itu peneliti memberikan masukan bagi peneliti selanjutnya, diataranya:

1) Game ini tidak memiliki fitur peta dalam permainannya sebagai alat petunjuk untuk pengguna agar tidak kebingungan mencari arah misi yang harus dia selesaikan;

2) Mengembangkan fitur high score sebagai nilai pencapaian pengguna dan fitur reward sebagai bentuk penghargaan bagi pengguna

\section{UCAPAN TERIMA KASIH}

Dalam penyusunannya, saya ingin menyampaikan rasa terima kasih kepada pihak-pihak yang telah memberikan saran, dukungan, dan kepercayaan yang begitu besar. Tidak terlepas dari pengawasan orang tua, dan saran dari rekan-rekan, semoga ini menjadi langkah yang lebih baik ke depannya dan dapat menjadi bahan pembelajaran untuk generasi mendatang yang diharapkan dapat menjadi tolak ukur, pembinaan dan bahan perbaikan di masa mendatang. 


\section{DAFTAR PUSTAKA}

[1] D. Tresnawati and I. Maulana, "Perancangan Dan Pembuatan Game Edukasi Pencegahan Nyamuk Demam Berdarah Berbasis Android," J. Algoritm., vol. 14, no. 2, pp. 358-367, 2017.

[2] S. A. Pramuditya, M. S. Noto, and D. Syaefullah, "Game Edukasi Rpg Matematika," Eduma Math. Educ. Learn. Teach., vol. 6, no. 1, pp. 77-84, 2017.

[3] F. H. Saputri and D. Pratiwi, "Pembuatan Game RPG 'Roro Jonggrang' dengan RPG Maker MV," in PROSIDING SEMINAR NASIONAL CENDEKIAWAN, 2016, pp. 1-9.

[4] D. P. Hermawan, "Efektivitas Penggunaan game edukasi berjenis puzzle, RPG dan Puzzle RPG sebagai sarana belajar matematika." Institut Teknologi Sepuluh Nopember, 2017.

[5] N. D. Safitri and R. M. T. Adi, "Pengembangan Game Edukasi Role Play Cerita Rakyat Indonesia Timun Emas Berbasis Android,” J. STT STIKMA Int., vol. 8, no. 1, pp. 15-22, 2018.

[6] M. Al-Hafi, "Game Endles Runing Si Kancil Menggunakan Finite State Machine," JATI (Jurnal Mhs. Tek. Inform., vol. 1, no. 1, pp. 577-582, 2017.

[7] D. P. Y. Ardiana and I. D. G. A. Pandawana, "Aplikasi Game Cerita Rakyat Bali Sebagai Sarana Pendidikan Karakter Anak Berbasis Mobile," Lontar Komput. J. Ilm. Teknol. Inf., vol. 8, no. 3, p. 208, 2017, doi: 10.24843/lkjiti.2017.v08.i03.p07.

[8] E. P. Putra, "Pembuatan Game Bergenre Tower Defense Dengan Judul" Selendang" Untuk Melestarikan Cerita Rakyat Jaka Tarub Bagi Anak." Surabaya: Institut Bisnis dan Informatika STIKOM Surabaya, 2017.

[9] D. Tresnawati and A. P. Nugraha, "Rancang Bangun Game Edukasi Sistem Tata Surya," J. Algoritm., vol. 14 , no. 2 , pp. 360-370, 2017.

[10] M. Erfan and T. Ratu, "Meningkatkan Minat Dan Hasil Belajar Mahasiswa Pada Perkuliahan Elektronika Dasar Melalui Digital Game-Based Learning," in Prosiding Seminar Nasional Pendidik dan Pengembang Pendidikan Indonesia, 2018, pp. 332-337.

[11] S. Soeheri, "DGBL-ID (Digital Game Based Learning) Sebagai Arsitektur Perancangan Game Edukasi," J. Eksplora Inform., vol. 6, no. 1, pp. 71-80, 2016.

[12] L. A. Prasetyo, "Pengembangan Game Edukasi Perakitan Komputer unuk Peserta Didik SMK Batik Perbaik Purworejo," J. Elektron. Pendidik. Tek. Inform. Vol. 4 Nomor, vol. 5, no. 1, 2015. 